\title{
EL RECURSO PREVIO DE INCONSTITUCIONALIDAD FRENTE A PROYECTOS DE ESTATUTOS DE AUTONOMÍA Y DE SU MODIFICACION ${ }^{1}$
}

\author{
CÉSAR AGUADO RENEDO \\ Profesor Titular de Derecho Constitucional \\ Universidad Autónoma de Madrid
}

\begin{abstract}
SUMARIO
I. El viaje de ida del recurso previo de inconstitucionalidad. II. El viaje de vuelta del recurso previo de inconstitucionalidad, de objeto (¿excesivamente?) restringido. III. El recurso previo de inconstitucionalidad es para todos los Estatutos. IV. Pero el control previo de las propuestas estatutarias no es un control imperativo. V. Aspectos temporales del recurso y efectos de su interposición. VI. El efecto de la Sentencia en el recurso previo de inconstitucionalidad: el imperativo coprotagonismo de las Asambleas autonómicas. VII. Referencia a la posibilidad del control constitucional posterior del Estatuto ya enjuiciado previamente. VIII. Como conclusión.
\end{abstract}

\section{EL VIAJE DE IDA DEL RECURSO PREVIO DE INCONSTITUCIONALIDAD}

Mediante Ley Orgánica 12/2015, de 22 de septiembre, el legislador del Tribunal Constitucional (TC) ha restablecido el recurso previo de inconstitucionalidad, tras haberlo previsto originariamente en la Ley Orgánica del Tribunal Constitucional (LOTC) y tras haberlo suprimido luego mediante Ley Orgánica 4/1985, de 7 de junio, por tanto antes de que hubiese transcurrido un sexenio de su entrada en vigor. Esta resurrección tres décadas después de su supresión, se restringe sin embargo en su objeto estrictamente a proyectos de Estatutos de

1 Estas páginas tienen su origen en la intervención en el Máster de Derecho Constitucional de la Universidad de Sevilla de 2015, dentro del programa «¿Reforma de la Constitución? ¿Qué reforma?». Aprovecho la ocasión para manifestar mi agradecimiento a las profesoras Ana Carmona y Encarnación Montoya por su gentil invitación para colaborar con ellas en la aludida actividad académica. 
Autonomía (EEAA) o de sus reformas: y así, la rúbrica literal del nuevo Título VI Bis de la Ley Orgánica del Tribunal Constitucional reza «Del recurso previo de inconstitucionalidad contra Proyectos de Estatutos de Autonomía y contra Propuestas de Reforma de Estatutos de Autonomía». Dado lo largo y reiterativo de la denominación del nuevo recurso, en adelante aquí se utilizará por lo general la expresión de recurso contra 'propuestas estatutarias', pues más que previsiblemente serán estas las que tengan lugar, y muy raramente lo serán proyectos de Estatuto: y ello porque con esta expresión debe entenderse que el legislador se está refiriendo a Estatutos tramitados por los cauces expresamente previstos en la Constitución (arts. 143, 144, 146, 151), es decir, a los que dan lugar a una nueva Comunidad Autónoma, no a los proyectos que sustituyen a un Estatuto anterior aunque su contenido suponga una novación de éste en su totalidad: parcial o total, la pretensión de alteración de un Estatuto previamente existente supone a estos efectos una modificación del mismo, es decir, técnicamente una "propuesta de reforma», y no un nuevo Estatuto, es decir, no un "proyecto de Estatuto». Así lo ha demostrado la práctica de los Estatutos reformados desde $2006^{2}$. De ahí, pues, la referencia que decíamos que, para abreviar, en adelante se hará habitualmente a las 'propuestas estatutarias'.

Las reflexiones que se expresan a continuación suscitadas por dicho viaje de ida y —aunque limitado en su objeto - ahora de vuelta, de tal recurso, dan por sabidos dos datos esenciales:

1. las críticas, tanto políticas como doctrinales, que durante el proceso de tramitación de la LOTC suscitó la inclusión de tal forma de control de constitucionalidad — preventiva—, no prevista por la Constitución como atribución del TC, sino resultado de una interpretación de la cláusula residual en que consiste el art. 161.1.d) CE. Esas críticas se fundaban en la escasa coherencia del control previo con la idea que sobre la naturaleza de dicho control se desprende claramente de la regulación del mismo en el texto constitucional, y en particular en su Título IX, que es, obviamente, el control posterior o represivo; una coherencia tan escasa que llevó a algunos a tildar de inconstitucional la opción de dicho control de constitucionalidad preventivo, quedando la cuestión zanjada por el mismo Tribunal Constitucional, en su Sentencia destinada justamente a enjuiciar la constitucionalidad de la reforma de su propia Ley reguladora que suprimía el citado recurso previo: en ella dejó sentado que se trataba de una

2 Las rúbricas de las leyes orgánicas que dieron lugar a la versión de siete nuevos EEAA en el proceso de innovación estatutaria iniciado en 2006, fueron enunciadas en todos los casos no como nuevos Estatutos, sino como reformas de los mismos: me permito remitirme al respecto a mi «Presentación» del Boletín de Documentación n. ${ }^{\circ}$ 35, 2011, del CEPC, Nuevos Estatutos de Autonomía comparados (http://www.cepc.gob.es/ biblioteca-y-documentaci\% $3 \% \mathrm{~B} 3 \mathrm{n} /$ documentacion/boletinesydossieresdedocumentacion/boletinesdocumentacion/bolet $\% \mathrm{C} 3 \% \mathrm{ADn}$-de-documentaci\%C3\%B3n-n35), p. 3. 
institución al margen de la Constitución, pero no contraria a ella (STC 66/1985, de 23 de mayo, FJ 2);

2. y el poco brillante papel, en general, de dicho recurso mientras estuvo vigente, consecuencia de la abusiva forma en que fue utilizado: como instrumento de obstrucción parlamentaria ${ }^{3}$.

Para una exposición más amplia de esto que se acaba de recordar, basta remitirse a algunos cualificados trabajos publicados apenas aprobada la supresión del recurso en cuestión ${ }^{4}$.

Ambos datos resultan cruciales, porque uno y otro justificarían de por sí la supresión del recurso previo de inconstitucionalidad que tuvo lugar.

En relación con el primero, es decir, con la distorsión que parece suponer el control previo en un sistema pensado para el control de constitucionalidad posterior, fue desarrollada por el antecitado legislador de 1985 en su Preámbulo. En concreto afirmó

3 PÉrez Royo, J., «Crónica de un error: el recurso previo de inconstitucionalidad contra leyes orgánicas», $R E D C$, n. ${ }^{\circ} 17,1986$, p. 161. La posibilidad de que el recurso previo pudiera ser utilizado de modo parlamentariamente obstruccionista había sido advertida de forma reiterada (cfr. los autores que recuerda en tal sentido el mismo trabajo que se acaba de citar, en nota 60), y la explica perfectamente el citado profesor sevillano: «A la vista del tiempo que el TC necesitaba para resolver un RPI, todo recurso interpuesto con tal carácter contra una ley orgánica aprobada entre el primer y segundo año de la Legislatura se resolvería casi en vísperas de las próximas Elecciones Generales, y los que se interpusieran a partir de la mitad de la Legislatura se resolverían casi con toda seguridad después. Esto podría impedir que la mayoría parlamentaria desarrollara normalmente su programa político y podría conducir, en última instancia, a que se alteraran gravemente las reglas del juego político». La Legislatura a la que se refiere el autor es a la II. , , esto es, aquella en la que el PSOE obtuvo una mayoría aplastante (202 Diputados) con la que procedió a confeccionar leyes orgánicas esenciales ignorando a la oposición parlamentaria como el otro componente de la institución representativa (lo que dio lugar a la expresión coloquial de «el rodillo parlamentario socialista»); este modo de proceder, llevó al principal Grupo de ésta, el Grupo Popular, a utilizar el recurso previo de inconstitucionalidad para entorpecer y retardar la aprobación de tales leyes: fueron concretamente los casos de la Ley Orgánica del Derecho a la Educación, de Libertad Sindical, de despenalización de interrupción del embarazo en determinados supuestos, de modificación de las elecciones locales o de incompatibilidades de Diputados y Senadores; a este conjunto se añadió la propia ley orgánica que suprimía el recurso previo. Todas ellas fueron impugnadas por el Grupo Popular (en el caso de la referida a la Libertad Sindical, concurrió con el Grupo vasco); en cambio, el proyecto de LOAPA, único de la I. ${ }^{a}$ Legislatura objeto del citado recurso, fue impugnado por las instituciones legislativas y ejecutivas catalanas y vascas, además de por 50 diputados.

Aunque la crítica al uso disfuncional del recurso previo ha devenido en lugar común, lo cierto es que, desde una perspectiva 'estadística', los resultados no apoyan esa idea: de los siete usos del mismo, en tres de ellos el resultado fueron Sentencias parcial (proyecto de LAOAPA y de despenalización de interrupción del embarazo en determinados supuestos) o totalmente (proyecto sobre incompatibilidades de Diputados y Senadores) estimatorias, lo que, con independencia ahora de que pueda considerarse en algunos de tales de casos discutible tal apreciación, no permite ignorar que en más de un $40 \%$ de los supuestos en que se utilizó el recurso previo cumpliera su finalidad de depuración del ordenamiento jurídico con anterioridad a la producción de efectos por leyes inconstitucionales. Por lo demás, desde una perspectiva democrático-parlamentaria, parece que para la tan crítica doctrina con el Grupo de la oposición que (ab)usó de tal instrumento, el terminante modo de proceder de la mayoría parlamentaria, por amplia que fuera, carecía de relevancia suficiente como para recibir algunos reproches.

4 En particular el acabado de citar de Pérez Royo y el de A. J. Gómez MonToro, «El control previo de constitucionalidad de proyectos de Estatutos de Autonomía y demás leyes orgánicas», en $R E D C$ n. $^{\circ} 22,1988$. 
- que dicho recurso impedía que las Cortes ejercieran su facultad legislativa de la forma plena que les corresponde, según el art. 66.2 CE, sin que éste prevea ningún límite a la misma (y límite sería el control constitucional preventivo de su labor);

— que para el TC, órgano jurisdiccional «y por tanto, alejado de los avatares de la práctica parlamentaria», el recurso previo le suponía verse «lanzado a una función que no responde al sistema de relación de poderes que la $\mathrm{CE}$ establece»;

- y que tal tipo de recurso tenía difícil encaje con el art. $91 \mathrm{CE}$, en cuanto dispone la sanción de la ley por el Rey tras la aprobación por las Cortes (el Preámbulo no alude a la interpretación del Tribunal en su ATC 120/1983, de 21 de marzo, que compatibilizó el recurso previo con el tenor del citado artículo constitucional, aunque tuviera algún Voto Particular que disintiese de tal solución).

Razones todas ellas que había esgrimido la doctrina crítica con la introducción de dicho tipo de control en la redacción original de la LOTC.

Sin embargo, nada dijo dicho legislador del uso desviado como instrumento de obstrucción parlamentaria del recurso previo, cuando sin duda fue mucho más decisiva para su supresión esta razón político-práctica que las anteriores. Que esto fue así lo evidencia el nuevo legislador, cuando en el Preámbulo de la L.O. $12 / 2015$ justifica la exclusión de todo objeto del recurso previo que reinstaura que no sean propuestas estatutarias, afirmando que con ello «Se evita... el principal reproche que mereció en el pasado esta institución jurídica cuando pudo ser utilizada por los grupos minoritarios para paralizar la entrada en vigor de normas legales, de carácter orgánico, aprobadas por las Cortes Generales».

Por el contrario, este mismo Preámbulo no alude a ninguna de las razones que se ha visto que indicaba el Preámbulo de 1985 para fundar la desaparición del recurso previo. Y si nada argumenta acerca de que tales motivos hayan dejado de existir, o de tener sentido, porque hayan variado las circunstancias, habrá de presuponerse que siguen plenamente vigentes hoy. De donde se concluye que hay que interpretar que, aun manteniéndose dichos motivos, sólo una razón de entidad suficiente para sobreponerse a ellos haría posible la reaparición del recurso previo de inconstitucionalidad.

Ese motivo lo ha encontrado el legislador, en exclusiva, en los Estatutos de Autonomía, un legislador por así decir potenciado, puesto que esta reintroducción del recurso previo tiene lugar a propuesta de los dos Grupos parlamentarios mayoritarios 5 .

5 En realidad, el Partido Popular la propuso antes, en 2006, con motivo de la importante reforma de la LOTC que se aprobaría en 2007, cuyo objeto esencial, como es de sobra sabido, fue la objetivación el recurso de amparo constitucional; evidentemente, la propuesta de dicho partido no prosperó. 


\section{EL VIAJE DE VUELTA DEL RECURSO PREVIO DE INCONSTITUCIONALIDAD, DE OBJETO (¿EXCESIVAMENTE?) RESTRINGIDO}

Además de la opinión favorable del Consejo de Estado a la reintroducción del recurso previo ${ }^{6}$, el Preámbulo de la L.O. 12/2015 explica, un tanto barrocamente, que ese motivo es una genérica "garantía de estabilidad y no fricción en la arquitectura jurídico-institucional del Estado» que debe observarse en el caso de los Estatutos de Autonomía, garantía que traduce en el «no siempre fácil equilibrio» entre, de un lado, «la especial legitimidad que tienen los Estatutos de Autonomía» en su condición de normas institucionales básicas en las que «intervienen tanto las Comunidades Autónomas como el Estado y, en ocasiones el cuerpo electoral mediante el referéndum», y, de otro, el «marco constitucional».

Así, pues, el legislador basa la nueva reincorporación del recurso previo en la singularidad de los Estatutos como normas, en cuanto en su elaboración y aprobación intervienen tanto las Comunidades Autónomas como el Estado y, muy en particular, en tanto que en ellos interviene también el cuerpo electoral autonómico mediante referéndum, razón ésta que sin duda se revela como la verdaderamente esencial por más que el legislador la dulcifique apuntando a que ello tiene lugar solo «en ocasiones». Sin duda, a lo que el Preámbulo de la Ley está aludiendo de forma implícita pero no por ello menos clara, es a la penosa experiencia habida con el nuevo Estatuto de Autonomía de Cataluña, una experiencia que haría incomprensible —creemos que en opinión prácticamente unánime- que pudiera volver a repetirse en futuras ocasiones (o semejantes ${ }^{7}$ ), sin que el legisla-

6 En el conocido Informe del mismo sobre la reforma de la Constitución efectuado por dicho órgano a instancias del Presidente Rodríguez Zapatero: Rubio Llorente, F. y Álvarez Junco, J., Informe del Consejo de Estado sobre la reforma constitucional (Texto del informe y debates académicos), CEPC, Madrid, 2006.

7 Nos referimos a que el Partido Nacionalista Vasco (partido que en estos momentos cuenta con el Gobierno vasco y con buena parte de los entes territoriales de dicha Comunidad), ha acordado en su reciente Asamblea (celebrada el 13-II-2016, en Pamplona) que el proyecto de nuevo Estatuto vasco que sustituya al vigente, y que será acordado con el Gobierno de la Nación antes de que se pronuncie el Parlamento de dicha Comunidad, ha de someterse a «consulta habilitante» entre el electorado de la misma antes de comenzar su tramitación en las Cortes, al objeto de constatar el apoyo con el que dicho texto cuenta entre la población; y sólo caso de que resulte que cuenta con el respaldo popular necesario se procedería a su envío a las Cortes para su correspondiente tramitación, elemento esencial de la cual es el referéndum correspondiente (la segunda consulta popular en la tramitación del proyecto estatutario, por tanto) ex art. 151.2.3. ( «Las bases [para la actualización del autogobierno vasco] que se acuerden fundamentarán la redacción de un proyecto político y jurídico de reforma del actual Estatuto de Autonomía que deberá refrendar el Parlamento Vasco. Una vez aprobado, consideramos conveniente que dicho proyecto de reforma estatutaria pudiera ser sometido, antes de iniciarse su tramitación ante las Cortes Generales, a una Consulta Habilitante por parte de la ciudadanía vasca»: Base 11, que constituye el último párrafo del Programa 2016-2020 del citado partido: http://www. eaj-pnv.eus/adjuntos/pnvDocumentos/18289_archivo.pdf, consultado el 14/08/2016; una referencia en prensa, p. ej., El País, 14/02/2016, p. 21: «El PNV pide votar el nuevo estatuto vasco en referéndum antes de llevarlo al Congreso»). Si lo que se pretende con esta idea es asegurar que el texto salido del Parlamento vasco no se alterará por las Cortes Generales, ello implicaría, evidentemente, desconocer la previsión constitucional del «común acuerdo» al que han de llegar aquél y éstas, e igual de evidente es que propicia la posibilidad de 
dor hubiera intentado ponerle remedio. Ahora bien, siendo claro que tal singularidad de los Estatutos existía desde el principio y que esta era la razón esencial por la que se contempló en la LOTC ${ }^{8}$, ha de concluirse que la supresión total del mismo fue un exceso o, si se quiere, un error, y a enmendarlo es a lo que viene su reintroducción.

Una reintroducción que cuenta con la opinión favorable de la gran mayoría de la doctrina que se ha ocupado del tema ${ }^{9}$, sobre todo a raíz de la anunciada reforma de la LOTC que acabaría aprobándose en 2007. Parecer favorable no sólo en relación con los proyectos estatutarios o sus reformas, sino también respecto de otros, señaladamente el de las reformas de la Constitución (al menos en su aspecto formal) $\mathrm{y}$, habida cuenta de los problemas que conlleva la inexistencia de tal posibilidad de control previo para algunas leyes orgánicas, comenzando por la reguladora del propio Tribunal Constitucional, también en otros casos en función de su «irreversibilidad $\gg^{10}$. Es una constatación que contrasta con las tan severas como generalizadas críticas doctrinales que mereció la introducción del recurso previo en la versión inicial de la LOTC y que, ciertamente confirmadas por su indebida utilización según antes se ha dicho, condujo a una desaparición del mismo que podría calificarse de muy celebrada. Pero, sobre todo, es una constatación que plantea si esta reintroducción limitada a las propuestas de reformas de EEAA o a eventuales Estatutos

una confrontación aún más severa que la habida con la experiencia de la actual Estatut catalán. Lo que aboca a concluir que no parece realista esperar la autorización estatal, necesaria ex art. 149.1.32. ${ }^{\text {a }} \mathrm{CE}$, de la consulta popular «habilitante» si su forma fuere la de referéndum; otra cosa es que tal consulta se llevase a cabo de modo jurídicamente informal, es decir, sin pretender ser un referéndum, con lo que ello comporta.

8 Que «Se trata[se] de un instrumento del que previsiblemente no se iba a hacer uso», tal y como interpretó PÉREZ Royo (ob. cit., p. 143), es indiferente a los efectos del razonamiento: con procedimientos estatutarios como el del art. $151 \mathrm{CE}$, la permanencia de la previsión devenía, más que conveniente, muy necesaria.

9 P. ej., y señaladamente dada su condición de Magistrado (y Presidente) ya emérito del propio Tribunal Constitucional, P. Cruz Villalón, «El control previo a los veinte años de su suspensión», en Fundamentos, n. ${ }^{\circ}$ 4, 2006. También significativo en el mismo sentido, por haber sido Fiscal Jefe ante el mismo Tribunal Constitucional y mantener la misma idea de la necesidad de un recurso previo de inconstitucionalidad frente a las propuestas de Estatuto, M. Montoro Puerto, «En torno a una posible recuperación del recurso previo de inconstitucionalidad», Economist E Jurist, n. ${ }^{\circ}$ 160, 2012, pp. 34-43. Años antes, M. A. Alegre MartíneZ se mostró decididamente partidario de la existencia de un control de constitucionalidad preventivo en su monografía, producto de su tesis doctoral, Justicia constitucional y control preventivo, Universidad de León, 1995; en ello ha venido insistiendo en diversas publicaciones posteriores sobre la cuestión. Se encuentran concentrados varios trabajos sobre la cuestión en PÉrez Tremps, P. (coord.), La reforma del Tribunal Constitucional, tirant lo blanch, Valencia, 2007, que recoge las Actas del V Congreso de la Asociación de Constitucionalistas de España y, salvo el de SAlazar Benítez, O., «Sobre la inconveniencia de introducir el recurso previo de inconstitucionalidad en los procedimientos de reforma estatutaria», los demás son totalmente partidarios de esa reintroducción: el más expresivo desde su mismo título, el de GIMÉNEZ SÁNCHEZ, I., «Recurso previo de inconstitucionalidad contra proyectos de reforma de Estatutos de Autonomía: viabilidad jurídica de una necesidad política», pero también el de Tajadura Tejada, J., «Reformas estatutarias y control previo de constitucionalidad» y Alegre Martínez, M. A., «Sobre la conveniencia de recuperar el recurso previo de inconstitucionalidad».

10 Cruz Villalón, ob. cit., pp. 283-4: la cursiva del término es del autor; Montoro Puerto o Alegre Martínez, p. ej., se han mostrado igualmente partidarios del restablecimiento del recurso previo respecto de tales leyes en una u otra medida. 
nuevos, ha sido una oportunidad perdida para preverlo también en los casos apuntados, en los que tendría una lógica difícil de rebatir ${ }^{11}$.

\section{EL RECURSO PREVIO DE INCONSTITUCIONALIDAD ES PARA TODOS LOS ESTATUTOS}

Limitado, por tanto, el objeto del recurso previo reintroducido a las propuestas estatutarias, el legislador lo ha previsto, eso sí, para todos los Estatutos tal y como se ha visto antes que argumenta el Preámbulo de la L.O. 12/2015: los que requieren de referéndum para su aprobación o reforma, y los que no. En principio, la necesidad de referéndum en la aprobación o reforma de un Estatuto, constituye una diferencia que hubiera legitimado a aquel legislador para restringir los supuestos de recurso previo, distinguiendo los EEAA que lo requieren de los que no, y limitando tal recurso solo a los primeros ${ }^{12}$. De hecho, tanto la rúbrica del Capítulo de la LOTC que regulaba el recurso previo inicialmente previsto, como el art. 79.1 y 2 del mismo, distinguían entre «proyectos de Estatutos de Autonomía» y proyectos «de leyes orgánicas», cuando, según es sabido, las que aprueban aquellos «Son leyes orgánicas...» (art. 81.1 CE), como, p. ej. y sin ir más lejos, ha señalado desde siempre el art. 27.2.a) LOTC al establecer como primero de los objetos del recurso de inconstitucionalidad «Los Estatutos de Autonomía y las demás Leyes orgánicas» ${ }^{13}$. La razón de tal diferenciación aparecía en el parágrafo a) del originario art. 79.1, que distinguía por un lado «El texto definitivo del proyecto de Estatuto que haya de ser sometido a referéndum en el territorio de la respectiva Comunidad autónoma en el supuesto previsto por el artículo ciento cincuenta y uno coma dos, tercero de la Constitución» y, por otro, «... los demás casos», en los cuales — señalaba dicho precepto- «... se entenderá que es texto definitivo del Estatuto de Autonomía el que, con arreglo al apartado siguiente, se establece para los demás proyectos de Leyes orgánicas»; esto es, la regulación originaria del recurso previo de inconstitucionalidad diferenciaba netamente entre los proyectos estatutarios destinados a ser sometidos a referéndum y todos «los demás», que consideraba proyectos de ley orgánica ${ }^{14}$. Con tal distinción se

$11 \mathrm{Al}$ punto de que, ante la inexistencia del recurso previo en esos otros supuestos que no fueren los de los EEAA y las reformas constitucionales, se ha propuesto alguna solución subsidiaria para los casos que CRUZ VILLALóN designa como «constitucionalmente sensibles» y que normalmente son leyes orgánicas: extender a los mismos la facultad de suspensión que actualmente le concede al TC su ley reguladora para las leyes autonómicas, como el citado autor apunta (op. cit., p. 289).

12 Como fue propugnado por el Grupo parlamentario de Izquierda Republicana-Izquierda Unida-Iniciativa per Catalunya Verds, en proposición de reforma de la LOTC (BOCG-Congreso de los Diputados, serie B, n. ${ }^{\circ}$ 198-1, de 9 de octubre de 2009).

13 La cursiva no es, obviamente, original. Luego volverá a aludirse a esta cuestión.

14 Como se ha tenido ocasión de ver al inicio de estas páginas, esta singularización entre Estatutos no se tradujo en la práctica, puesto que los siete supuestos en que se utilizó el recurso previo de inconstituciona- 
hubiera contribuido a una de las aspiraciones más connotadas de las fuerzas nacionalistas: subrayar la diferenciación simbólica entre las CCAA tenidas por «nacionalidades»y las tenidas por «regiones» (art. $2 \mathrm{CE}$ ).

Pero, de un lado, si tal diferenciación hubiera resultado acaso factible antes de los EEAA conocidos «de segunda generación», que comienzan a aprobarse en 2006, cuando sólo los elaborados por el cauce del art. 151 CE requerían de referéndum para su aprobación (art. 151.2 CE) y para su reforma (art. 152.2 $\mathrm{CE}$ ), a partir de ese momento las «ocasiones» (utilizando el término del Preámbulo de la Ley 12/2015 referida a los referéndums estatutarios) en las que debe o puede ser consultado el cuerpo electoral autonómico de que se trate, se han ampliado, y Estatutos que no fueron aprobados ni modificados con tal requisito, es decir, Estatutos aprobados por el cauce de los arts. 143-146 CE, lo han incorporado como requisito para su modificación ${ }^{15}$; lo mismo podría suceder con otros Estatutos en el futuro ${ }^{16}$, de modo que las posibilidades de que se reproduzca una experiencia como la del Estatut catalán aumentan sensiblemente, y a evitarlas es a lo que se dirige, clara y principalmente, el recurso previo ahora retomado.

En todo caso, y de otro lado, no nos cabe duda de que, aunque no hubieran introducido esta exigencia dichos Estatutos de los arts. 143-146, el recurso previo hubiese debido ser igualmente aplicable a todas las leyes estatutarias, puesto que su naturaleza de norma institucional básica es idéntica, sean o no sometidos a referéndum, y ceñir únicamente a los Estatutos del art. $151 \mathrm{CE}$ el objeto del recurso previo, hubiese comportado introducir una distinción entre estas y aquellas normas estatutarias (con la connotación que ello comportaría), no en su rango ni en su fuerza, pero sí en su valor, esto es, por utilizar la significativa expresión del TC, en el tratamiento de su «privilegio jurisdiccional $»^{17}$, con posibilidad de control previo antes de convertirse en norma en unos casos, los menos, y no en los demás.

\section{PERO EL CONTROL PREVIO DE LAS PROPUESTAS ESTATUTARIAS NO ES UN CONTROL IMPERATIVO}

Ahora bien, concluido lo anterior, es decir, reinstaurado el recurso previo sólo para las propuestas estatutarias, pero para todas ellas, cabe preguntarse si no hubiera sido preferible imponer el control previo de constitucionalidad siempre y en todo caso, y no dejarlo a la voluntad de los legitimados. Así ha sido propues-

lidad fueron siempre contra leyes orgánicas no estatutarias, es decir, que no aprobaban ni reformaban Estatutos de Autonomía.

15 Casos de los Estatutos de Valencia, Andalucía y Aragón, para los diversos supuestos que regulan.

16 Otra cosa es la impropiedad, a nuestro modesto juicio, de que Estatutos que no han requerido tal exigencia para su aprobación, la incorporen para su alteración.

17 STC 163/1995, de 8 de noviembre, FJ 4. 
to por más de uno ${ }^{18}$, así sucede en algún sistema comparado próximo al nuestro para leyes relevantes y, desde luego, no puede tildarse de propuesta infundada ${ }^{19}$.

De entrada, sin embargo, la obligatoriedad del control previo de todas las propuestas estatutarias (que en tal caso dejaría de ser un recurso para constituir un trámite más en su iter normativo), casaría mal con un modelo de control posterior (o represivo), que es el que indudablemente ha dispuesto el constituyente español, tal y como comentábamos al inicio. Confirmación clara de ello parece que lo constituye el régimen constitucional del control previo de los tratados internacionales que, tras exigir la reforma de la Norma Fundamental caso de que se vaya a firmar un acuerdo internacional con estipulaciones contrarias (art. 95.1 CE), no establece el control imperativo previo en el caso de los Tratados, sino su mera posibilidad, pues «puede requerir» el mismo el Gobierno o cualquiera de las Cámaras nacionales parlamentarias, según dispone el art. 95.2 (pese al dato fundamental que hubiera aconsejado teóricamente su carácter imperativo siempre: la indisponibilidad de estos por el poderes nacionales, algo que no sucede en el caso de los EEAA, donde cualquier reforma constitucional que incidiere en ellos, automáticamente comportaría su modificación en la medida correspondiente).

A nuestro juicio, por una parte la mayor susceptibilidad de politización de su uso que comporta el carácter facultativo de la interposición del recurso previo, en función de las circunstancias políticas concretas en cuyo contexto se tramite un proyecto estatutario y de la correlación de fuerzas políticas que las protagonicen, no compensa la mayor coherencia con la presunción de constitucionalidad de la actuación del legislador estatutario (que en el caso — recuérdese - es un legislador compuesto, autonómico y estatal, aunque la norma resultante sea evidentemente de resultado único e imputable al legislador estatal ex art. 81.1 CE). Y, por otra parte, y desde una perspectiva puramente pragmática, y precisamente por ello más principal si cabe, la generalización total del recurso previo para todas las propuestas estatutarias supondría una alteración mayor aún del desenvolvimiento de la actividad del TC, puesto que, como se verá poco más adelante, tal recurso tiene preferencia en su tramitación y resolución, por relevante que sean los demás asuntos que tenga sobre la mesa el Tribunal.

18 P. ej., por Montoro Puerto, ob. cit., p. 39; y más recientemente, por Villaverde Menéndez, I., «El control previo de constitucionalidad de las normas con rango de ley. Crónica de un escéptico», Revista catalana de Derecho Público, n. ${ }^{\circ}$ 49, 2014, p. 31.

19 I. Villaverde razona que «si lo que se pretende es evitar un «choque de legitimidades» y los «graves perjuicios» que puede ocasionar una tardía sentencia del TC en vía de recurso sucesivo, el control previo debería ser obligatorio y de oficio. Otorgar legitimidades activas a sujetos o a órganos siempre conlleva poner a disposición de la voluntad de la minoría parlamentaria derrotada, o de un Gobierno de la Nación opuesto al proyecto de reforma estatutaria, o frustrado por no haber podido controlar el proceso hasta su final o el contenido del nuevo EA, el arma política de torcer el acuerdo mayoritario; aunque sea por un tiempo. A mi juicio, el control previo debería instituirse quizá como una suerte de procedimiento de obligada observancia para el caso de normas como los EE. AA., leyes orgánicas o de reforma constitucional. Un control de oficio similar en su diseño al previsto para los tratados internacionales (art. 95.2 CE)» (ob. cit., p. 31). 
Por último, el carácter facultativo de un control previo, tiene como complemento natural la posibilidad de un control posterior sobre la misma norma, que es lo que en nuestro caso preveía ya la versión originaria del mismo, y es lo que lógicamente sigue previendo la nueva regulación, como ya se ha adelantado y como se volverá a ver después; y el sentido de esa posibilidad parece que disminuye en bastante medida si el control previo resultase imperativo.

\section{ASPECTOS FORMALES DEL RECURSO Y EFECTOS DE SU INTERPOSICIÓN}

Visto lo relativo al objeto del recurso previo reinstaurado, procede señalar los aspectos procedimentales del mismo más relevantes, a la luz de la finalidad pretendida por el nuevo legislador del mismo, que, como se ha visto que señala el Preámbulo, es lograr lo que de forma manierista el mismo denomina la «garantía de estabilidad y no fricción en la arquitectura jurídico-institucional del Estado».

La L.O. 12/2015, que en esencia viene a revivir el mismo artículo 79 LOTC que fue derogado por la citada L.O. 4/1985 limitado al objeto de las propuestas estatutarias, establece un procedimiento ad hoc para el recurso previo, con su legitimación, objeto específico, plazos de interposición y de resolución y efectos de la interposición del recurso y de su pronunciamiento.

Por lo que hace a la legitimación, el nuevo art. 79.3 LOTC la ciñe a los legitimados para recurrir los Estatutos de Autonomía, coherentemente con la limitación al objeto del recurso previo, que no cabe ahora respecto de las demás leyes orgánicas. En consecuencia, es la que establece el art. 32 LOTC $^{20}$. En lo que más interesa aquí, se seguirá dando, pues, la misma circunstancia en relación con los grupos de oposición, usuarios naturales de este instituto jurídico. Sin embargo, las elecciones generales de Diciembre de 2015 han traído la importante novedad de que caben —al menos en teoría - más combinaciones de parlamentarios en las Cámaras nacionales para alcanzar los 50 precisos para interponerlo, habida cuenta de la mayor fragmentación de la representación parlamentaria que se ha producido; o sea, deja de ser una posibilidad prácticamente al alcance sólo del principal partido de la oposición, como la experiencia venía evidenciando hasta la fecha, sin perjuicio de la posibilidad de interposición de dicho recurso por los ejecutivos y legislativos de otras Comunidades Autónomas que se sintieren afectadas en sus competencias por los proyectos de nuevos Estatutos o por sus reformas (art. 32.2 LOTC), desde el momento en que, como ley orgánica que formalmente es, el Estatuto resulta norma estatal ${ }^{21}$.

20 «Están legitimados para el ejercicio del recurso de inconstitucionalidad cuando se trate de Estatutos de Autonomía y demás Leyes del Estado, orgánicas o en cualesquiera de sus formas..., a) El Presidente del Gobierno.b) El Defensor del Pueblo.c) Cincuenta Diputados.d) Cincuenta Senadores» (art. 32.1 LOTC).

21 «Para el ejercicio del recurso de inconstitucionalidad contra las Leyes... del Estado que puedan afectar a su propio ámbito de autonomía, están también legitimados los órganos colegiados ejecutivos y las 
El concreto objeto del recurso previo no es el proyecto de Estatuto o de su reforma sin más, sino una vez «aprobado por las Cortes Generales» y publicado en el Boletín Oficial de éstas, por tanto cuando las Cámaras parlamentarias nacionales se han pronunciado definitivamente sobre el mismo, siendo la aparición en tal Boletín el instante que supone el dies a quo de los tres días que vuelve — pues el mismo plazo establecía el originario art. 79- a disponer la regulación del recurso restablecido, para poder interponerlo. Dicha interposición supone la suspensión (automática) de «todos los trámites subsiguientes» (art. 79.4), explicitando que, de ser uno ellos el referéndum autonómico, éste no podrá convocarse hasta que el TC no se haya pronunciado y, en su caso, se hayan modificado o suprimido los preceptos declarados inconstitucionales (art. 79.5); algo que reitera más adelante (79.7), lo que vuelve a evidenciar la principal razón de ser de la reforma, tal y como ya hemos señalado, que no es tanto la depuración del ordenamiento cuanto tratar de evitar a toda costa la confrontación de legitimidades entre cuerpos electorales autonómicos y representantes de la soberanía nacional.

Una vez interpuesto, es claro que el verdadero quid de la efectividad del control previo estriba en la adopción del pronunciamiento en un plazo sensiblemente limitado sobre la premisa de que el TC está, por definición, siempre sobresaturado: van de suyo los efectos negativos que comportaría mantener una norma de la entidad de un Estatuto suspensa largo tiempo, de modo que cabe asegurar que, en la mayoría de las situaciones, los perjuicios que ocasionarían una prolongada pendencia de un recurso previo no compensarían el beneficio de la depuración constitucional previa teóricamente perseguida con tal instrumento. El legislador se ha mostrado bien consciente de ello, como muestra, de entrada, el establecimiento del plazo de seis meses que ha dispuesto para que el TC se pronuncie sobre el control requerido, frente a lo que acaecía en la previsión originaria, en la que no se preveía plazo para la resolución. Pero más significativa aún de esa conciencia del legislador es la improrrogabilidad que determina de dicho plazo. En este sentido, aunque las aclaraciones pueden venir bien en cuanto despejen eventuales dudas, esta improrrogabilidad hace en rigor innecesarias las que añade a continuación el precepto acerca de la reducción de plazos de su tramitación y de la preferencia de este tipo de resoluciones «sobre el resto de asuntos en tramitación» (art. 79. 6) para lograr la observancia de tal plazo, puesto que, aunque no las especificase, el Tribunal debería operar con una y/u otra fórmula para lograr emitir su resolución en tiempo. Nótese que, como antes se ha dicho ya, esta preferencia pone de relieve la necesaria excepcionalidad conque ha de ser concebido el uso del recurso previo, desde el momento en que la preferencia que necesaria-

Asambleas de las Comunidades Autónomas...» (art. 32.2 LOTC). Procede recordar en tal sentido, puesto que ha quedado dicho que la causa real de la reintroducción del recurso previo contra Estatutos de Autonomía y sus reformas ha sido la experiencia con el nuevo Estatut catalán, que éste fue impugnado, entre otros actores, por hasta cinco Comunidades Autónomas (cfr., p. ej., al respecto la antes citada «Presentación» a Nuevos Estatutos de Autonomía comparados, en los recursos electrónicos del CEPC). 
mente ha de tener la resolución del mismo altera el orden de resolución de los demás procesos sobre asuntos, ya en tramitación o ya repartidos aunque el TC aún no haya comenzado a conocer de los mismos.

\section{EL EFECTO DE LA SENTENCIA EN EL RECURSO PREVIO DE INCONSTITUCIONALIDAD: EL NECESARIO COPROTAGONISMO DE LAS ASAMBLEAS AUTONÓMICAS}

Según ha quedado dicho, el recurso previo constituye un proceso constitucional y, como tal, su resolución ha de adoptar la forma de Sentencia ex art. 86.1 LOTC. Aunque esto parece una obviedad, el artículo que regula el recurso previo se refiere siempre a la conclusión de tal proceso con el término «pronunciamiento», evitando el de Sentencia, algo que ya sucedía en la regulación original. El Preámbulo de la L.O. 12/2015, sin embargo, sí alude a la «...la Sentencia estimatoria...» del recurso (como es sabido, la LOTC carece de Exposición de Motivos, por lo que no puede buscarse una aclaración equivalente en la regulación originaria del recurso previo). En todo caso, aunque no se hubiese especificado la referencia en el Preámbulo, ninguna duda puede caber de que el «pronunciamiento» al que se refiere el art. 79 ha de observar la forma de Sentencia como proceso constitucional que es.

En consecuencia, de concluir el TC que no hay aspectos inconstitucionales en el proyecto recurrido, así ha de declararlo en su Sentencia. La tramitación seguirá entonces su curso, incluido, en su caso, el referéndum tal y como especifica el art. $79.7 .^{\circ}$, algo que va de suyo, de manera que, como antes se decía, la especificación legal ha de entenderse como un subrayado significativo de tal trámite.

Por el contrario, de concluir que el proyecto contiene preceptos inconstitucionales, la decisión del TC deberá concretar los que lo son y, junto con ellos, aquellos a los que la inconstitucionalidad alcance por conexión o consecuencia, lo mismo que corresponde a la declaración de inconstitucionalidad en un procedimiento de control constitucional habitual (art. 39 LOTC) ${ }^{22}$.

La Sentencia que constata la inconstitucionalidad de preceptos, por su parte, impide la continuación de la tramitación del procedimiento sin su supresión o su modificación «por las Cortes Generales» (art. 79.8. ${ }^{\circ}$ ), determinación que difiere de lo que la versión inicial del recurso designaba como «el órgano competente» para efectuar tal supresión o modificación. A mi juicio, esta disposición es la que plantea la cuestión quizá más sobresaliente del nuevo recurso previo.

22 Aunque esta extensión de la inconstitucionalidad no la preveía la redacción originaria del art. 79, la coherencia sustantiva del recurso previo en primer lugar, y su naturaleza de verdadero proceso constitucional, hacían indefectible tal efecto extensivo. 
Aparentemente, tal determinación del legislador es coherente con la naturaleza de los EEAA, que, como se ha comenzado recordando, normativamente son, ex art. 81.1 CE, leyes orgánicas ${ }^{23}$ que, ex art. 147.1 CE, integran el ordenamiento del Estado ${ }^{24}$, de manera que atribuir la modificación de la misma al órgano legislativo estatal resulta lógico. Ahora bien, esa naturaleza de ley orgánica del Estatuto y esa su pertenencia al ordenamiento estatal, todo ello indudable, tiene lugar en su calidad de norma perfecta. La cosa es distinta, sin embargo, mientras se está elaborando la misma (ya en su versión originaria, ya en su versión reformada), es decir, mientras aún es propuesta de norma cuyo contenido resulta susceptible de acuerdo entre las dos voluntades diferenciadas que concurren en la elaboración de los EEAA.

Y así, en el caso de todos los EEAA, pero en particular de todos aquellos que, como se ha visto, constituyen sin duda la principal razón de ser de la reintroducción del recurso previo que nos ocupa por tener que someterse a aprobación referendaria, la propia Constitución determina un proceso que garantiza la intervención de las Comunidades Autónomas de las cuales constituirán su norma institucional básica. A esa precisa idea obedecen las normas emanadas en su día por las Presidencias de las Cámaras parlamentarias nacionales para la tramitación de las reformas de los $\mathrm{EEAA}^{25}$ en cuanto prevén la posibilidad de retirada por la Comunidad Autónoma de la propuesta de reforma de su Estatuto si la Asamblea de la Comunidad de que se trate no está conforme con las modificaciones que quieran introducir las Cortes Generales al texto propuesto por aquélla (aptdo. 5. ${ }^{\circ}$ de ambas normas), siempre que las Cortes no se hayan pronunciado sobre tal propuesta. Una vez realizado ese pronunciamiento, la propuesta resulta indisponible para la Asamblea autonómica. De este modo, si el TC entendiese inconstitucionales contenidos previamente acordados por ambos Parlamentos, el autonómico y el nacional, de forma que hubiera que modificarlos o eliminarlos del proyecto estatutario en tramitación, a quien habrá de dirigirse el TC es, ciertamente,

23 Retomando la alusión inicial a la polémica sobre la naturaleza de los EEAA, baste señalar que, si el Consejo de Estado en su Informe sobre la reforma de la Constitución antes citado, afirmó que «Pese a estar aprobados por ley orgánica, los Estatutos no son leyes orgánicas, sino una fuente normativa distinta. Ni las leyes orgánicas pueden modificar los Estatutos, o desconocerlos, ni los Estatutos pueden ignorar o modificar las leyes orgánicas existentes» (p. 174), el Tribunal Constitucional ha señalado posteriormente que «Los Estatutos de Autonomía se integran en el Ordenamiento bajo la forma de un específico tipo de ley estatal: la ley orgánica, forma jurídica a la que los arts. 81 y 147.3 CE reservan su aprobación y su reforma. Su posición en el sistema de fuentes es, por tanto, la característica de las leyes orgánicas» (STC 31/2010, de 28 de junio, FJ 3), lo que, cuando menos a los efectos que aquí interesan, resulta definitivo.

24 Estado en el sentido de ente territorial con un ordenamiento distinto de los ordenamientos de los entes territoriales autonómicos (Oberstaat), no Estado en sentido global (Gesamtstaat) que incluye a estos.

25 Resolución de la Presidencia del Congreso de los Diputados de 16 de marzo de 1993 y Norma Supletoria de la Presidencia del Senado de 30 de septiembre de 1993: a estos efectos, y conforme a lo comentado al principio acerca de la indistinción normativa en la práctica entre reforma e innovación de EEAA ya existentes, tales normas resultan plenamente aplicables a la novación total de Estatutos presentes en el ordenamiento, no así a los puramente nuevos, es decir, a los que den lugar a hipotéticas nuevas CCAA. 
a las Cortes Generales como órgano al que, de aprobarse con los preceptos declarados inconstitucionales, resultaría imputable la inconstitucionalidad del proyecto. Pero las Cortes no podrían, por sí solas, esto es, sin el concurso de la Asamblea de la Comunidad de la que partió formalmente el texto de la reforma, expurgarlo o alterarlo en un sentido que los parlamentarios nacionales entendiesen constitucionalmente conforme: la inconstitucionalidad de preceptos estatutarios declarada en el recurso previo de inconstitucionalidad, directamente o por conexión o consecuencia, conlleva que la Asamblea autonómica que elaboró el proyecto tenga la posibilidad de optar entre el resultado que exige esa declaración de inconstitucionalidad (mediante la eliminación total de los preceptos en cuestión, o mediante su sustitución por otros compatibles con la Constitución en el sentido que crea más oportuno), o el mantenimiento del Estatuto en su versión vigente hasta el momento.

El tratamiento de tal cuestión podrá ser realizada por la Asamblea en Pleno o sólo por una Comisión que designe en su seno, según estime conveniente la misma, en función, se supone, de la mayor o menor trascendencia del contenido del proyecto declarado constitucionalmente disconforme. Lo que sin duda no cabe, es entender que puedan decidir sobre ello las delegaciones de dichas Asambleas a las que se refieren las normas de las Presidencias de las Cámaras antes aludidas, porque tales delegaciones están pensadas solamente para la exposición o explicación (o defensa si se quiere), del proyecto estatutario en el seno de las Cortes Generales, no para remediar la inconstitucionalidad del mismo constatada por el $\mathrm{TC}^{26}$.

\section{REFERENCIA A LA POSIBILIDAD DEL CONTROL CONSTITUCIONAL POSTERIOR DEL ESTATUTO YA ENJUICIADO PREVIAMENTE}

En fin, la regulación del recurso previo de inconstitucionalidad finaliza con la explicitación, que ya adelantamos, de que el pronunciamiento del mismo «no prejuzga» el control del constitucionalidad del Estatuto que pueda llevarse a cabo tras su entrada en vigor (art. 79.9), tal y como prevé el ya citado art. 27.1.a) LOTC. Es una declaración de inexistencia de fuerza de cosa juzgada no sólo material, de modo que deja claro que el TC puede revisar su propia doctrina expuesta con ocasión del control previo de preceptos estatutarios, sino también formal, pues los mismos preceptos estatutarios que fueron declarados constitucionales con anterioridad a su vigencia, pueden luego ser declarados inconstitucionales sin

26 Esa finalidad explica que en el supuesto general, el de los Estatutos que han seguido el cauce de los arts. 143-146 CE, la delegación de la Asamblea autonómica encargada de presentar la propuesta estatutaria ante el Pleno del Congreso no pueda sobrepasar el número de tres integrantes (aptdo. $3 .^{\circ} .1$ de la RPCD), sea cual sea el número de fuerzas con representación parlamentaria en aquélla. 
haber variado su literalidad. El motivo del mantenimiento (porque también figuraba ya en la versión originaria del recurso previo) de esta disposición, más allá de preservar la coherencia teórica en tanto cohonesta el control previo con el control a posteriori, ha de buscarse en el margen que proporciona al TC para permitirle volver sobre preceptos estatutarios enjuiciados con carácter previo (acaso bastante tiempo atrás), a la vista bien de los efectos que ha generado su aplicación y que no eran previsibles en el momento en que se conoció de ellos, bien de nuevas circunstancias sobrevenidas que pueden incidir en la conformidad constitucional inicialmente declarada.

\section{COMO CONCLUSIÓN}

De todo lo expuesto se infiere que la restitución al ordenamiento del recurso previo de inconstitucionalidad contra las propuestas estatutarias ha de considerarse una decisión más que conveniente, en la línea de lo que venía proponiendo la mayor parte de la doctrina, imprescindible, tras la traumática experiencia del actual Estatuto de Autonomía de Cataluña. Cuando, interrumpido el proceso de actualización de los EEAA que comenzara en 2006, quedan aproximadamente la mitad de ellos pendientes de una probable reforma actualizadora ${ }^{27}$, y cuando se ha incorporado el referéndum a algunos de los nuevos textos estatutarios que antes no lo preveían, las posibilidades de que pueda reproducirse algún supuesto similar al citado son evidentes. Esa experiencia traumática y esas posibilidades, que como hemos repetido, constituyen la causa sustantiva de la reintroducción del recurso previo de inconstitucionalidad, no se cohonesta precisamente bien con el comienzo del Preámbulo de la L.O. 12/2015, que asevera que «El Estado Autonómico pactado en la Transición y diseñado por la Constitución Española de 1978 ha funcionado razonablemente bien durante los más de treinta y cinco años que la norma fundamental lleva en vigor»: todo depende de lo que se entienda por «razonable», pero no parece que de ello constituya muestra precisamente la necesidad en la que se ha visto el legislador de reintroducir el recurso previo de inconstitucionalidad, cuya supresión tanto acuerdo suscitó en su día.

En todo caso, no obstante, la conclusión sobre su necesidad no es incompatible con un escepticismo, relativo al menos, sobre su eficacia para lograr el objetivo que con él se pretende: evitar la colisión de legitimidades entre las instituciones representativas (Asamblea autonómica de que se trate y Cortes Generales) de un lado, y la institución superior en materia de interpretación y salvaguarda de la Constitución (el Tribunal Constitucional) de otro. Lo que puede esperarse del

27 Aunque, desde luego, no hay indicios de que resulte urgente, contra lo que parecía a partir del momento en que Cataluña anunció la reforma del suyo: como es sabido, el verdadero motor del desenvolvimiento del Estado autonómico no ha resultado ser otro que el principio de emulación. 
recurso previo es la desactivación jurídica del conflicto, pero no su desactivación política. Esta segunda desactivación dependerá, simplemente, del espíritu o intención que presida el comportamiento de las fuerzas políticas concernidas por el control. Si esa intención es de enfrentamiento, tales fuerzas siempre tendrán a su disposición el argumento de la «objeción democrática» al control de la ley, que cuestiona, o mejor, rechaza, que un colegio reducido (un tribunal, como es el TC) pueda anular una norma aprobada por representantes democráticamente elegidos, tanto más si sobre la misma se pronuncia el cuerpo electoral ${ }^{28}$, es decir, siempre podrán enfatizar la contradicción, de producirse, en la actuación del órgano jurisdiccional y la significación democrática de las instituciones parlamentarias que han acordado el texto de la propuesta estatutaria recurrida. Tal objeción se disuelve en la juridificación del poder —incluido el del cuerpo electoral, aun cuando sea el cuerpo electoral total de un Estado- juridificación que supone toda Constitución verdaderamente tal, pues no otra cosa es la conquista del constitucionalismo que domeñar el poder, también el poder de la mayoría, sometiéndolo a pautas previamente acordadas que sólo cabe alterar siguiendo un procedimiento ad hoc igualmente acordado ${ }^{29}$. Pero este es un argumento que parece aún demasiado abstracto, o intelectual, como para ser esgrimido en la batalla política. En este sentido, p. ej., no hace falta un análisis contrafactual intenso sobre cómo hubieran procedido las fuerzas políticas catalanas que vienen sustentando el proceso soberanista si hubiese estado vigente al tiempo de su tramitación el recurso previo de inconstitucionalidad y se hubiere interpuesto con (sólo) idéntico resultado al que supuso la STC 31/2010 30 . Se comprenderá, en fin, el escepticismo que

28 Sobre la cuestión puede verse Fossas EsPADALER, E., «El control de constitucionalidad de los estatutos de autonomía», Revista catalana de Derecho Público, n. ${ }^{\circ} 43,2011$. El autor muestra ejemplos de control de las Constituciones de Estados norteamericanos, de los Länder alemanes y los Estatutos de las Regiones italianas; en el caso de aquellos textos que han sido sometidos a referéndum, sin embargo, apunta la diferencia entre lo que ocurre en el caso de los EE. UU., donde las leyes y Constituciones estatales son objeto de control sin problema (las leyes y la Constitución federales no son objeto de referéndum) y Francia, donde el refrendo popular de una normativa hace que el Consejo Constitucional se declare incompetente para su control; ahora bien, no puede dejar de añadirse necesariamente en este segundo caso que el refrendo lo es allí de toda la nación, no de una parte de la misma: por eso dice bien I. Villaverde que «Precisamente la percepción distinta de la soberanía y el papel de la ley en el sistema constitucional francés explica que el control previo se alce como expresión acabada de la conciliación entre la legitimidad enfrentada de la ley «soberana» y de la «constituida» jurisdicción constitucional» (ob. cit., n. ${ }^{\circ} 41$ ).

29 Así lo ha expuesto el TC español: «... el cuerpo electoral no se confunde con el titular de la soberanía, esto es, con el pueblo español (art. 1.2 CE), aunque su voluntad se exprese a través de él. Este cuerpo electoral está sometido a la Constitución y al resto del Ordenamiento jurídico (art. 9.1 CE), en tanto que el pueblo soberano es la unidad ideal de imputación del poder constituyente y como tal fundamento de la Constitución y del Ordenamiento» (STC 12/2008, de 29 de enero, FJ 9): conviene aclarar que el cuerpo electoral al que se refiere la cita es el cuerpo electoral nacional o conjunto, de donde se desprende que, evidentemente, con mayor razón procede el mismo razonamiento en supuestos de fracciones de cuerpos electorales.

30 Decimos «sólo», porque de ordinario se pasa por alto por quienes la critican, que los numerosos Votos Particulares a la STC sobre el Estatut (5 de los 10 Magistrados que conformaron el Pleno en el caso), lo fueron en su gran mayoría porque consideraron improcedente (y lo expresaron severamente) el uso generalizado de la técnica de la interpretación conforme para evitar lo que, indudablemente a su juicio, hubieran debido 
invade en relación con la efectividad práctica del recurso previo restablecido respecto de su finalidad, en los eventuales casos de propuestas estatutarias políticamente problemáticas.

Aun con todo, el efecto de evitar la confrontación en el ámbito solamente jurídico no resulta precisamente baladí y, por ello, el juicio que nos merece la reintroducción del recurso previo es positiva y, más aún, y concordando con las opiniones doctrinales en su momento referidas, entendemos que seguramente se ha perdido la oportunidad de que esa reintroducción se llevase a cabo en el ámbito más extenso que aconsejan razones muy fundadas sobre, al menos, propuestas de reformas constitucionales y de la propia Ley Orgánica reguladora del Tribunal Constitucional.

$$
* * *
$$

TITLE: The preliminary appeal of unconstitutionality against draft statutes of autonomy and its modification

ABSTRACT: The article is an analysis of previous unconstitutional appeal, reintroduced as the Spanish Constitutional Court attribution decades after it was repealed, although now restricted exclusively to draft Statutes of autonomy or amendments thereto. The main reason for its restoration (the referendum of the Statutes approved by way of art. 151); indistinction of the Statutes of autonomy as an object thereof; maintain consistency of its optional character and not turn it into an imperative procedure; non-extendible deadline for sentencing; and relative skepticism that the previous unconstitutional appeal serves to achieve what is assumed that the legislature pursues the same time, it is the essential aspects addressed in the work.

RESUMEN: El artículo consiste en un análisis del recurso previo de inconstitucionalidad reintroducido como atribución del Tribunal Constitucional español décadas después de haber sido derogado, aunque restringido ahora exclusivamente a proyectos de Estatutos o de sus reformas. La razón principal de su restablecimiento (que es el referéndum de los Estatutos del art. 151); la indistinción de los Estatutos como objeto del mismo; la coherencia de mantener su carácter facultativo y no convertirlo en un trámite imperativo; el plazo improrrogable para su resolución y el relativo escepticismo de que sirva para lograr lo que se presupone que persigue el legislador con el mismo, son los aspectos esenciales que se abordan en el trabajo.

KEY WORDS: Statute of Autonomy, preliminary appeal of unconstitutionality referendum, democratic objection, organic laws.

Palabras Clave: Estatuto de Autonomía, recurso previo de inconstitucionalidad, referéndum, objeción democrática, leyes orgánicas.

FECHA DE RECEPCIÓN: 15.09.2016

FECHA DE ACEPTACIÓN: 21.09.2016

ser numerosas declaraciones de inconstitucionalidad; si estas se hubiesen producido en el pronunciamiento de un recurso previo, estamos convencidos de que la reacción política, y bajo su mediatización la popular, no hubiera sido un ápice distinta a la que se produjo como consecuencia del control posterior del Estatut. 
